\title{
Antineutrophil Cytoplasmic Antibody-associated Vasculitis Management 2020: Where Are We Now?
}

\section{David Jayne ${ }^{1}$ (D)}

The management of antineutrophil cytoplasmic antibody (ANCA)-associated vasculitis (AAV) has come a long way from the first postmortem descriptions of the diseases in the 1930s and 1950s. Pivotal phases have been the introduction of glucocorticoids (GC) and cyclophosphamide (CYC), the association with ANCA in the 1980s, and consensus classification and nomenclature systems from 1990 onwards $^{2}$. These advances laid the foundations for larger-scale clinical investigations that have informed both the development of recommendations statements in the 2000s and the evaluation of newer therapies ${ }^{3}$. In parallel with these activities have been improvements in physician training and healthcare delivery, which have shortened diagnostic delay, and improved mortality and endstage renal disease risks ${ }^{4}$. Statements to guide AAV management have now been produced at national and international levels, and an update of the Canadian Vasculitis Society (CanVasc) 2015 statement is published in this edition of The Journal of Rheumatology 5 .

This is an extensive piece of work with 39 recommendation statements, 15 of them new for this update covering diagnosis, drug therapies, eosinophilic granulomatosis with polyangiitis (EGPA), children, monitoring, and prophylaxis. So what is new? Solid-phase assays for proteinase 3-ANCA and myeloperoxidase (MPO)-ANCA are the preferred initial serologic tests reflecting superior performance when compared to indirect immunofluorescence (cytoplasmic or perinuclear ANCA). There is more discussion on GC dosing as better data have emerged and momentum builds to limit doses. The place of rituximab (RTX) has been extended to relapse prevention; plasma exchange use is more restricted; and mycophenolate mofetil (MMF) is an

${ }^{1} D$. Jayne, MD, FMedSci, Department of Medicine. University of Cambridge, Cambridge, UK.

$D J$ has received research grants from Chemocentryx, GSK, Roche/Genentech, and Sanofi-Genzyme. He has received consultancy fees from Astra-Zeneca, Boehringer-Ingelheim, Chemocentryx, Chugai, GSK, Infla-RX, Novartis, and Takeda.

Address correspondence to Dr. D. Jayne, Box 157, Department of

Medicine, Addenbrookes Hospital, Cambridge CB22QQ, UK.

Email:Dj106@cam.ac.uk. alternative induction option. The use of biomarkers to guide drug dosing during remission maintenance, and the duration of maintenance treatment is reviewed. Areas that have received less attention, and have fewer data, include the delivery of healthcare to patients with vasculitis, patient education and its role in decision making, and the tailoring of drug therapy in older patients.

The key themes influencing the design of induction regimens are the opposing aims of wanting to further reduce steroid exposure while achieving faster and more complete remission. Although the safety profile and 6-month efficacy of RTX is attractive, the slow effect for aggressive presentations demands higher steroid dosing until its therapeutic effect is manifest. This has encouraged combinations of RTX with CYC, which have been shown to require less CYC and, in an observational cohort, to permit GC removal after two weeks ${ }^{6}$. Both methotrexate and MMF appear in the recommendations as alternative induction agents on the basis of relatively small trials with noninferiority hypotheses and in the presence of conventionally dosed GC. What is less clear from the initial reports is that both are associated with high early relapse rates and subsequent requirement for RTX or CYC?

Despite a histologic classification as a "pauci-immune" vasculitis, in comparison to immune complex disorders such as systemic lupus erythematosus, complement dysregulation occurs in the pathogenesis of $\mathrm{AAV}^{8}$. Lower circulating complement $\mathrm{C} 3$ component levels associate with worse outcomes and complement factors, including factor $\mathrm{B}, \mathrm{C} 3 \mathrm{~d}$, and C5b-9, are present in renal biopsies from patients with $\mathrm{AAV}^{9}$. Attention has focused on complement $\mathrm{C} 5 \mathrm{a}$ due to its known role as an anaphylatoxin, its ability to prime neutrophils for ANCA-induced activation, and the abrogation of experimental AAV by $\mathrm{C} 5 \mathrm{a}$ receptor blockade ${ }^{10,11}$. A specific oral inhibitor of the C5a receptor, avacopan, was shown in the phase II CLEAR study to be an alternative induction agent to GC and in the phase III ADVOCATE study to lead to more sustained remissions at 52 weeks, when avacopan with placebo prednisone was compared to a prednisone-tapering regimen ${ }^{12,13}$. In addition to concom-

See CanVasc AAV recommendations, page 555 
itant reductions in GC exposure and toxicity with avacopan, there were greater improvements in renal indices including renal function recovery. The prospect of a safer alternative to steroids is exciting, and it will be important to further study the ability of avacopan to recover organ function and determine the duration of benefit. A monoclonal antibody to C5a, vilobelimab, is in phase II studies in AAV (ClinicalTrials.gov: NCT03895801 and NCT03712345).

Personalization or stratification of induction therapy remains a challenge with terms such as "severe" widely used with varying definitions, and those with "limited" disease [i.e., granulomatosis with polyangiitis (GPA) restricted to the upper and lower respiratory tract] at risk of eye, ear, and lung damage. Indeed, the British Society of Rheumatology took the view that all patients with AAV were severe ${ }^{14}$. An example of this uncertainty comes from the RITAZAREM (RTX maintenance) trial when patients entering were classified as "major" or "minor" according to the presence of disease activity items deemed severe. Physicians were allowed to select a higher or lower dose GC regimen, but there was no particular preference for higher dosing with major disease manifestations and no difference in therapeutic efficacy between regimens for either severity group ${ }^{15}$. We lack clinically useful biomarkers to guide selection or dosing of induction agents, although some pharmacogenomic markers have been identified ${ }^{16,17}$.

In many ways, the issues facing relapse prevention are more complex. Although we now have two trials demonstrating the superiority of RTX over azathioprine, the duration and dosing of RTX remain unclear and an increasing proportion of patients are developing secondary immunodeficiency caused by repeated cycles of $\mathrm{B}$ cell depletion ${ }^{15,18}$. Risk stratification is not discussed, although we have evidence supporting several variables at baseline and over the disease course that influence relapse risk (Table 1). It appears that ANCA is a more useful biomarker after RTX than oral immunosuppressive/GC maintenance, but data around the utility of measuring B cell counts are conflicting ${ }^{19,20}$. These issues emphasize another key theme for drug development-longer-term control of immune dysregulation. Depleting B cells with RTX is not sufficient to normalize
T cell dysregulation and when B cells return, the disease takes off. The therapeutic options being considered include combined treatment with the anti-B cell activating factor monoclonal belimumab, use of more potent anti-CD20, or targeting T cells directly.

Patients with EGPA are more likely to follow a refractory course than those with GPA and microscopic polyangiitis (MPA), and more likely to suffer higher cumulative GC exposure, driven in part by chronic asthma and nasosinus disease. They were excluded from clinical trials of RTX and recommendations have relied on quite old studies from the French Vasculitis Study group (FVSG). The successful testing of the anti-interleukin (IL) 5 monoclonal antibody mepolizumab is directly of benefit to patients and is encouraging development of other anti-IL-5 agents, such as benralizumab (ClinicalTrials. gov: NCT04157348) ${ }^{21}$. At the same time, genomic studies have shown that MPO-ANCA is a key biomarker with immunogenetics, the same as that for MPO-ANCA-positive MPA/GPA, whereas polymorphisms of other genes including those relating to eosinophil activation are found in the ANCA-negative subgroup $^{22}$. There appear to be differences in response to RTX between ANCA-positive and -negative EGPA, and possibly better response to anti-IL-5 therapy in the ANCA-negative group $^{23}$. These developments will drive a new classification of EGPA and help guide drug selection for individual patients.

Many older goals of research into AAV are being met: reductions in GC and CYC exposure, managing relapse risk, and better understanding of the immunopathology of vasculitis, particularly, that mediated by ANCA autoantibodies. The disease frequency and phenotypic heterogeneity has been a challenge for clinical investigators and has inspired the development of collaborative networks, such as the FVSG, European Vasculitis Society (EUVAS), Vasculitis Clinical Research Consortium (VCRC), Japan Research Committee for Intractable Vasculitis, and CanVasc; global participation across these networks has supported a sequence of recent studies. The increasing pace of clinical research accelerated by more pharmaceutical company involvement underlines the priority of translating advances to routine practice. Hopefully, this guidelines group will be busy again in another five years.

Table 1. Factors increasing relapse risk in ANCA-associated vasculitis (GPA and MPA).

\begin{tabular}{|c|c|c|}
\hline Baseline Factors & Factors During Follow-up & Treatment-related Factors \\
\hline Diagnosis of GPA & History of previous relapse & $\begin{array}{l}\text { Lower cumulative cyclophos- } \\
\text { phamide exposure }\end{array}$ \\
\hline PR3-ANCA & Persisting ANCA-positive after induction & $\begin{array}{l}\text { Oral immunosuppressive and/ } \\
\text { or glucocorticoid withdrawal }\end{array}$ \\
\hline Ear, nose, and throat involvement & $\begin{array}{l}\text { Conversion from ANCA-negative to } \\
\text {-positive or rise in ANCA (especially } \\
\text { after RTX) }\end{array}$ & RTX withdrawal \\
\hline Lower serum creatinine & Shorter time to B cell return after RTX & $\begin{array}{l}\text { MTX or MMF induction } \\
\text { (PR3-ANCA) }\end{array}$ \\
\hline
\end{tabular}

ANCA: antineutrophil cytoplasmic antibody; GPA: granulomatosis with polyangiitis; MMF: mycophenolate mofetil; MPA: microscopic polyangiitis; MTX: methotrexate; PR3: proteinase 3; RTX: rituximab. 


\section{REFERENCES}

1. Fahey JL, Leonard E, Churg J, Godman G. Wegener's granulomatosis. Am J Med 1954;17:168-79.

2. Jennette JC, Falk RJ, Bacon PA, Basu N, Cid MC, Ferrario F, et al. 2012 revised International Chapel Hill Consensus Conference Nomenclature of Vasculitides. Arthritis Rheum 2013;65:1-11.

3. Lapraik C, Watts R, Bacon P, Carruthers D, Chakravarty K, D'Cruz D, et al; BSR and BHPR Standards, Guidelines and Audit Working Group. BSR and BHPR guidelines for the management of adults with ANCA associated vasculitis. Rheumatology 2007;46:1615-6.

4. Hilhorst M, Wilde B, van Paassen P, Winkens B, van Breda Vriesman P, Cohen Tervaert JW; Limburg Renal Registry. Improved outcome in anti-neutrophil cytoplasmic antibody (ANCA)-associated glomerulonephritis: a 30-year follow-up study. Nephrol Dial Transplant 2013;28:373-9.

5. Mendel A, Ennis D, Go E, Bakowsky V, Baldwin C, Benseler SM, et al. CanVasc consensus recommendations for the management of antineutrophil cytoplasm antibody-associated vasculitis: 2020 update. J Rheumatol 2021;48:555-66.

6. Pepper RJ, McAdoo SP, Moran SM, Kelly D, Scott J, Hamour S, et al. A novel glucocorticoid-free maintenance regimen for anti-neutrophil cytoplasm antibody-associated vasculitis. Rheumatology 2019;58:260-8.

7. Faurschou M, Westman K, Rasmussen N, de Groot K, Flossmann O, Höglundet P, et al; European Vasculitis Study Group. Brief Report: long-term outcome of a randomized clinical trial comparing methotrexate to cyclophosphamide for remission induction in early systemic antineutrophil cytoplasmic antibody-associated vasculitis. Arthritis Rheum 2012;64:3472-7.

8. Chen M, Jayne DR, Zhao MH. Complement in ANCA-associated vasculitis: mechanisms and implications for management. Nat Rev Nephrol 2017;13:359-67.

9. Augusto JF, Langs V, Demiselle J, Lavigne C, Brilland B, Duveau $A$, et al. Low serum complement $\mathrm{C} 3$ Levels at diagnosis of renal ANCA-associated vasculitis is associated with poor prognosis. PLoS One 2016;11:e0158871.

10. Schreiber A, Xiao H, Jennette JC, Schneider W, Luft FC, Kettritz R. C5a receptor mediates neutrophil activation and ANCA-induced glomerulonephritis. J Am Soc Nephrol 2009;20:289-98.

11. Xiao H, Dairaghi DJ, Powers JP, Ertl LS, Baumgart T, Wang Y, et al. C5a receptor (CD88) blockade protects against MPO-ANCA GN. J Am Soc Nephrol 2014;25:225-31.

12. Jayne DR, Bruchfeld AN, Harper L, Schaier M, Venning MC, Hamilton P, et al; CLEAR Study Group. Randomized trial of C5a receptor inhibitor avacopan in ANCA-associated vasculitis. J Am Soc Nephrol 2017;28:2756-67.
13. Merkel P, Jayne D, Yur H, Schall TJ, Becker P. A randomized, double-blind, active-controlled study of avacopan in anti-neutrophil cytoplasmic antibody (ANCA)-associated vasculitis [abstract]. Ann Rheum Dis 2020;79:8.

14. Ntatsaki E, Carruthers D, Chakravarty K, D'Cruz D, Harper L, Jayne D, et al; BSR and BHPR Standards, Guidelines and Audit Working Group. BSR and BHPR guideline for the management of adults with ANCA-associated vasculitis. Rheumatology 2014;53:2306-9.

15. Smith RM, Jones RB, Specks U, Bond S, Nodale M, Aljayyousi R, et al. Rituximab as therapy to induce remission after relapse in ANCA-associated vasculitis. Ann Rheum Dis 2020;79:1243-9.

16. Alberici F, Smith RM, Fonseca M, Willcocks LC, Jones RB, Holle JU, et al. Association of a TNFSF13B (BAFF) regulatory region single nucleotide polymorphism with response to rituximab in antineutrophil cytoplasmic antibody-associated vasculitis. J Allergy Clin Immunol 2017;139:1684-7.e10.

17. Cartin-Ceba R, Indrakanti D, Specks U, Stone JH, Hoffman GS, Kallenberg CG, et al; RAVE-Immune Tolerance Network Research Group. The pharmacogenomic association of $\mathrm{Fc} \gamma$ receptors and cytochrome $\mathrm{P} 450$ enzymes with response to rituximab or cyclophosphamide treatment in antineutrophil cytoplasmic antibody-associated vasculitis. Arthritis Rheumatol 2017;69:169-75.

18. Guillevin L, Pagnoux C, Karras A, Khouatra C, Aumaitre O, Cohen P, et al; French Vasculitis Study Group. Rituximab versus azathioprine for maintenance in ANCA-associated vasculitis. N Engl J Med 2014;371:1771-80.

19. Alberici F, Smith RM, Jones RB, Roberts DM, Willcocks LC, Chaudhry A, et al. Long-term follow-up of patients who received repeat-dose rituximab as maintenance therapy for ANCA-associated vasculitis. Rheumatology 2015;54:1153-60.

20. McClure ME, Wason J, Gopaluni S, Tieu J, Smith RM, Jayne DR, et al. Evaluation of PR3-ANCA status after rituximab for ANCA-associated vasculitis. J Clin Rheumatol 2019;25:217-23.

21. Steinfeld J, Bradford ES, Brown J, Mallett S, Yancey SW, Akuthota $\mathrm{P}$, et al. Evaluation of clinical benefit from treatment with mepolizumab for patients with eosinophilic granulomatosis with polyangiitis. J Allergy Clin Immunol. 2019;143:2170-7.

22. Lyons PA, Peters JE, Alberici F, Liley J, Coulson RM, Astle W, et al. Genome-wide association study of eosinophilic granulomatosis with polyangiitis reveals genomic loci stratified by ANCA status. Nat Commun 2019;10:5120.

23. Teixeira V, Mohammad AJ, Jones RB, Smith R, Jayne D. Efficacy and safety of rituximab in the treatment of eosinophilic granulomatosis with polyangiitis. RMD Open 2019;5:e00905. 